\title{
Com muito orgulho: novidades
}

\author{
Harley E. A. Bicas
}

Já a partir deste número, os leitores dos Arquivos Brasileiros de Oftalmologia notarão algumas diferenças na revista. Uma das novas seções é a de resumos dos trabalhos publicados pela Revista Mexicana de Oftalmologia. Inequivocamente, esta é uma das melhores publicações de Oftalmologia na América Latina, abrindo-se com a maior divulgação de seus artigos, entre nós, uma boa oportunidade de conhecermos melhor a reconhecida criatividade mexicana, para a solução de problemas freqüentemente similares aos nossos. De fato, com características de cultura e população relativamente parecidas, apresentando dificuldades sócio-econômicas e engenhosidade para resolvê-las não muito diferentes, México e Brasil têm dado exemplos ao mundo de como emergir dignamente para melhores condições de vida. De resto, tem-se tornado exemplar a "hermanedad" que, entre latino-americanos, vem aproximando essas duas nações. Por outro lado, nesse promissor intercâmbio, resumos de artigos dos Arquivos Brasileiros de Oftalmologia aparecerão, também, na Revista Mexicana de Oftalmologia. Maior visibilidade das publicações de lá e cá, será, talvez, fonte de produções em colaboração; provavelmente de reforços mútuos de conhecimento; mas, com absoluta segurança e pelo menos, de inspirações recíprocas, inovadoras e criativas. Que este intercâmbio que agora se inicia possa ser núcleo de agregação de outros.

Outra novidade é a da publicação da Conferência do Conselho Brasileiro de Oftalmologia que, doravante, pretende-se que se torne regular. Assim, com aparecimento a cada dois anos, pois tal aula magna é proferida nos Congressos Brasileiros de Oftalmologia "gerais" (os dos anos ímpares, em oposição aos de Prevenção da Cegueira e Reabilitação Visual, nos anos pares), a periodicidade dessa seção tornar-se-á muito demorada o que, entretanto, não impede que ela deixe de ser assim considerada. Lamentando-se que não tenha sido possível publicar as Conferências oficiais do C.B.O. anteriores, uma nota editorial apresentando a mais recente resgata, pelo menos, suas memórias.

Publica-se também, no próximo número, uma série de textos articulados sob o título de "Processos Editoriais". Representam notas relativas às apresentações dos Simpósios dos Arquivos Brasileiros de Oftalmologia realizados em 2002, no XV Congresso Brasileiro de Prevenção da Cegueira e Reabilitação Visual, em Curitiba e em 2003 no XXXII Congresso Brasileiro de Oftalmologia, em Salvador. Preparadas pelos Editores da revista, elas se destinam não apenas aos conselheiros editoriais regulares e aos "ad hoc", mas a todos que se interessem pelo assunto que lhes dá título. Devem ser lidas como incentivo à formação de quadros editoriais, de cujas faltas nosso país se ressente.
Finalmente, a sobremesa: a possível solução para um problema que já nos vem afligindo há algum tempo. Aliás, um bom problema. Trata-se se virmos - involuntariamente, até que se chegasse a uma decisão - represando a publicação de artigos já aprovada por nossos conselheiros editoriais e editores. $\mathrm{O}$ represamento, na verdade, começou lentamente e origina-se da aumentada oferta de publicação de matérias, por sua vez causada por vários fatores concorrentes: o do crescimento contínuo do número de autores; o da maior produtividade científica nacional, positivamente alavancada por nossos cursos de pós-graduação; o da maior visibilidade dos A.B.O. e suas melhores qualificações pelas Universidades e agências oficiais de fomento à pesquisa científica no Brasil; e o do decidido reconhecimento, implícito e explícito, do valor dos A.B.O. pela comunidade científica nacional. Talvez um leitor mais atento possa ter notado que de 532 páginas em 2000 , passamos a 610 em 2001, a 706 em 2002 e já a 544 com apenas quatro números em 2003. Na verdade, apenas se decidiu que esse crescimento deva ser acelerado. Pois além da solução de aumento da paginação, com acolhimento de mais artigos, havia a de "arrochar" as exigibilidades para a publicação; ou a de intensificar a periodicidade da revista, passando-a a mensal. Mas esta seria a mais onerosa, não só pelo crescimento de despesas postais como pela demanda por agilização nos processos de publicação (possivelmente exigindo ampliação do quadro de funcionários), sem, em contra-partida, trazer benefícios além do de antecipação de um mês na publicação de metade dos artigos. Claro que comparada com a atual, tal proposta é mais vantajosa (a leitores e autores), embora as circunstâncias presentes aconselhem a não tomá-la. Mas temos a certeza de que, mais cedo ou mais tarde, deverá vir a ser implementada.

Já a alternativa de maior filtração dos artigos recebidos é elitista, numa quadra da ciência nacional que, parece, ainda não pode admitir tal luxo. Sem dúvida, a linha academicista orientada a tais propósitos tenderia, inicialmente, a elevar o nível de nossa publicação conquanto, possivelmente, ao custo de esterilizar promessas autorais emergentes, ao desencorajá-las a uma competição exacerbada por espaços. A médio e longo prazos os resultados poderiam, então, ser desastrosos. Entretanto, com a persistência dos atuais índices de novos oftalmologistas a cada ano e o aumento crescente da massa crítica de artigos de nossa especialidade enviados à publicação, chegar-se-á, também e inexoravelmente, a essa condição.

Assim, a alternativa de engrossar cada número, embora transitória, firmou-se como a mais adequada. Sigamos, provisoriamente, por esse caminho. 